\title{
Brittle diabetes: long-term control with a portable, continuous, intravenous insulin infusion system
}

\author{
JOHN BAYLISS
}

\begin{abstract}
A young woman had severe brittle diabetes mellitus that was critically unmanageable with all conventional insulin treatment. Continuous subcutaneous and intramuscular infusions of insulin also failed to control her metabolic instability. Use of a continuous intravenous infusion, however, whereby a portable, variablerate, battery-operated syringe pump delivered insulin through a subcutaneously tunnelled central venous catheter, resulted in good control. When she was receiving hourly intramuscular insulin injections (a mean of $778 \mathrm{IU}$ daily) mean blood glucose concentrations had been $22 \cdot 1.4 \quad \mathrm{mmol} / 1 \quad(398+25 \quad \mathrm{mg} /$ $100 \mu 1)$. After she had received the intravenous infusion for one month as an outpatient mean blood glucose concentration was $8.2+0.46 \mathrm{mmol} / 1(148+8 \mathrm{mg} / 100 \mu \mathrm{l})$ and only $80 \mathrm{IU}$ insulin daily was required.

Follow-up after over five months of use showed that few complications had occurred. The system is simple to use and safe, and the diabetes had been stabilised such that she could enjoy a near-normal life style.
\end{abstract}

\section{Introduction}

In recent years techniques of continuous insulin infusion have been developed in an attempt to provide more physiological metabolic homeostasis in diabetes mellitus in the hope that this will reduce later complications. " Subcutaneous insulin infusion achieves excellent metabolic control in stable: drabetes, ${ }^{3-}{ }^{-7}$ but patients with "brittle" diabetes remain uncontrolled. ${ }^{8}$ It is this small group of patients, whose lives are se totally disrupted by the chaotic nature of their disease; who would benefit most from good diabetic control, intramuscular insulin infusion may provide better control in such cases. ${ }^{8}$ The diabetic instability and resistance to insulin in many of these patients is probably

Hillingdon Hospital, Uxbridge, Middlesex JOHN BAYLISS, MA, MRCP, medical registrar due to a combination of excessive local degradation of insulin and irregular absorption from the subcutaneous site. ${ }^{9-11} \mathrm{I}$ report on a patient with severely brittle diabetes, uncontrolled by subcutaneous and intramuscular insulin infusion, who responded to long-term intravenous insulin infusion given via a portable, variable-rate system, which allowed her to return to a nearnormal life style.

\section{Case report}

The patient developed insulin-dependent diabetes subacutely in 1974 when aged 15. Twice-daily subcutaneous injections of soluble insulin and a diabetic diet were started, and her condition remained well controlled for one year but then she suddenly developed severe ketoacidotic coma after omitting only three insulin doses. Subsequently she required over 70 emergency admissions, usually because of ketoacidosis but also several times because of profound hypoglycaemia. She was unable to continue full-time education, and her life revolved entirely around the management of her diabetes.

Varying the dosages, types, and timing of her insulins with impeccable dietary control, guar gum, and high-fibre diets failed to improve control. Subcutaneous insulin infusion failed to lessen the rapid fluctuations in blood glucose concentrations, so intramuscular infusion was attempted. Although a little more effective, this technique failed technically because of repeated blockage and dislodgement of the cannula. In early 1981 she required hourly intramuscular injections, often totalling over 1000 IU insulin daily. but her blood glucose concentration rarely fell below $15 \mathrm{mmol} / \mathrm{l}(27 \mathrm{C} \mathrm{mg} / 100 \mathrm{ml}$ ) and she repeatedly developed ketoacidotic coma. Her injection sites were becoming increasingly fibrotic but not lipodystrophic.

There was no evidence tc suggest any emotional or other psychological cause for the brittleness of her diabetes, so further investigations were performed in an attempt to elucidate the nature of her insulin resistance.

Serum free insulin concentration was measured by radioimmunoassay ${ }^{12}$ : two hours after an intramuscular injection of 100 IC rapidacting, purified pork insulin (Leo Neutral, Nordisk Ltd) the serum free insulin concentration was very low at $15.0 \mathrm{pmol} / 1(2.1 \mathrm{mU} / \mathrm{l})$ and the blood glucose concentration $22.8 \mathrm{mmol} / 1(410 \mathrm{mg} / 100 \mathrm{ml}$ ). The following day, when her condition had been stabilised with an intravenous insulin infusion $(2 \mathrm{IU} / \mathrm{h})$, the serum free insulin concentration was $37.3 \mathrm{pmol} / 1(5.2 \mathrm{~mL} / 1)$ and the blood glucose concentration $9.3 \mathrm{mmol} / 1(167 \mathrm{mg} / 100 \mathrm{ml})$. These figures show considerable failure of absorption of insulin from. her muscle. Measurement of insulin binding for beef and pork antibodies was performed by incubation 
with radiolabelled insulin ${ }^{13}$ : during intravenous infusion of purified pork insulin there was $19.5 \%$ binding of beef insulin and $9.5 \%$ binding of pork insulin. These results, which are within the normal range and had not increased over the preceding four years, suggest that there was no excessive neutralisation of insulin. Counterregulatory hormones were assayed during a fairly "unstable" day: concentrations of growth hormone, cortisol, glucagon, somatostatin, vasoactive intestinal peptide, gastrin, and pancreatic polypeptide were all normal, suggesting that insulin antagonism played no part in the brittleness of her diabetes.

Because she had been admitted so many times in coma requiring intravenous treatment all peripheral venous access was lost and repeated central venous cannulation became increasingly difficult. It was therefore decided that a system should be implanted for longterm intravenous insulin infusion to control her diabetes.

\section{METHOD}

A Silastic Hickman catheter (Schuco Ltd, London) was inserted under local anaesthesia via the right subclavian vein into the right atrium, ${ }^{14}$ the position being checked by image intensifier. The distal end of the catheter was tunnelled subcutaneously down the anterior chest wall, emerging at the level of and midway between the nipples. The infraclavicular wound was then closed over the catheter. A Dacron cuff on the catheter lies within the subcutaneous tunnel inciting fibrosis to enhance fixation of the catheter and to act as an infection barrier. Insulin is delivered through this catheter continuously from a $10 \mathrm{ml}$ syringe driven by a variable-rate, batteryoperated, small portable infusion pump (Pye Model MS 16). The syringe contains $100 \mathrm{IU}$ purified pork insulin (Leo Neutral) diluted in physiological saline, with 100 IU heparin added to prevent blockage of the catheter and to reduce the risk of sepsis. ${ }^{15}$ One syringe usually suffices for a 24 -hour period. The distal exit site on the chest wall was cleaned daily with povidine-iodine ointment (Betadine) and covered with gauze until complete healing had occurred (about one month). The syringe may be connected to the catheter with a Luer locking extension tube for greater mobility. It is advisable to use only Luer locking connections, including a Luer locking syringe to avoid accidental disconnection.

The patient checked her capillary blood glucose concentration every two to four hours, using Dextrostix reagent strips (Ames Ltd, Bucks) and reading the result on a calibrated reflectance meter (Hypocount, Hypoguard Ltd, Suffolk). She adjusted the infusion rate empirically, according to her blood glucose concentration, level of activity, and food intake; the basal rate of infusion was usually $2 \mathrm{IU} / \mathrm{h}$ at night and 4-6 IU/h by day, the rate being increased to $10-20 \mathrm{IU} / \mathrm{h}$ for two or three hours to cover meals (fig 1).

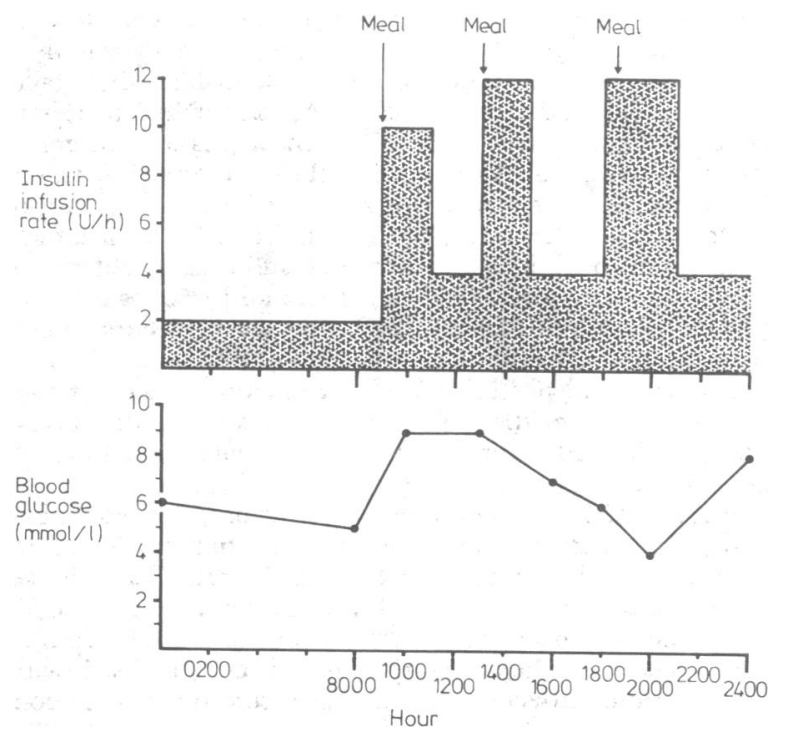

FIG 1-Rate of infusion of intravenous insulin and blood glucose profile during typical 24-hour period at home.

Conversion: SI to traditional units-Blood glucose: $1 \mathrm{mmol} / 1$ $\approx 18 \mathrm{mg} / 100 \mathrm{ml}$.

\section{RESULTS}

The mean blood glucose concentration over a typical four-day period when she was receiving hourly intramuscular injections had been $22 \cdot 1+$ SEM $1.4 \mathrm{mmol} / 1(398: 25 \mathrm{mg} / 100 \mu \mathrm{l})$ and the mean daily dose of insulin $778 \mathrm{IU}$. During the first four days of the intravenous regimen the mean blood glucose concentration fell to $8.8: 0.95$ $\mathrm{mmol} / \mathrm{l}(158-17 \mathrm{mg} / 100 \mu \mathrm{l})$ and the daily dose of insulin to $88 \mathrm{IU}$. After one month at home mean blood glucose concentration over a typical four days was $8.2: 0.46 \mathrm{mmol} / \mathrm{l}(148.8 \mathrm{mg} / 100 \mu \mathrm{l})$ and daily insulin dose 80 IU (fig 2).

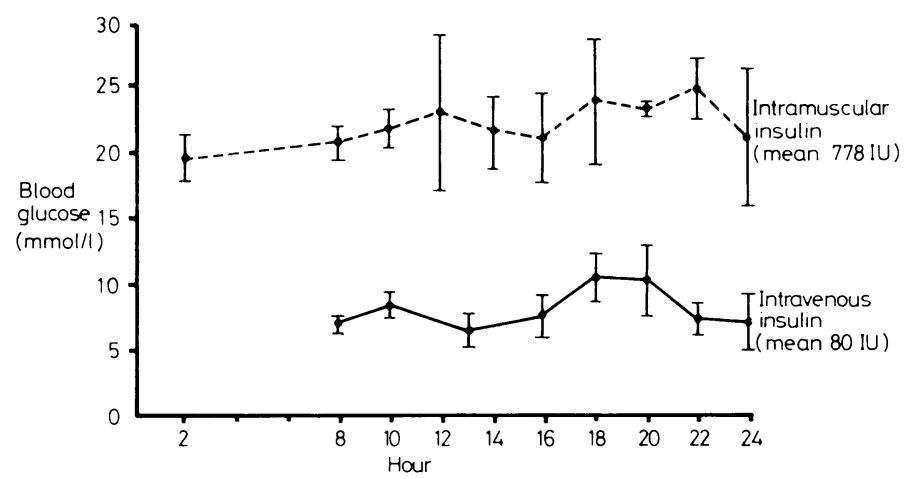

FIG 2-Blood glucose profiles during hourly intramuscular injections and continuous intravenous infusion of insulin.

Conversion: SI to traditional units-Blood glucose: $1 \mathrm{mmol} / 1 \approx 18 \mathrm{mg} /$ $100 \mathrm{ml}$.

After seven months of use the system was still operating successfully and no wound infections or thrombotic complications had occurred. A pinpoint leak that had developed at the distal end of the catheter had been repaired with ease, under sterile conditions, using a special repair kit supplied by the manufacturers. Accidental disconnection of the syringe from the catheter had occurred once while the patient was asleep and had resulted in a staphylococcal bacteraemia; this had been readily cleared with intravenous cefuroxime for 10 days, with no recurrence of infection and without removal of the catheter. A Luer locking syringe was subsequently used to prevent such disconnections.

She found the system simple to use, easy to care for, and only minimally obtrusive under her clothing. Despite the frequent sampling of capillary blood there was no scarring of the fingertips and no loss of fine finger sensation. For the first time in many years she felt extremely well and was leading a normal active life.

\section{Discussion}

Several reports have linked excessive insulin requirements to abnormal degradation of insulin at the subcutaneous injection site, which usually responds readily to intravenous insulin,,$^{11} 1617$ but resistance to intramuscular absorption is rare. In this patient the prolonged excessive use of muscle injection sites may have further reduced muscle absorption. Although using aprotinin may improve insulin absorption in this condition, ${ }^{11}$ diabetic control remains rather unstable.

Subcutaneously tunnelled right atrial catheters have been used successfully for long-term intravenous feeding, are simple to insert, and are fairly safe to use, even outside hospital. ${ }^{18}$ Complications such as occlusion of the catheter, infection of the exit site, and accidental disconnection are avoidable if adequate care is taken; leakage is easily repairable. Catheterrelated septicaemia is rare, occurring once in every 5.5 patient years in one series, ${ }^{18}$ and may often be treated without removal of the catheter. The system is small, easy to use, and acceptable to the patient. The use of a computer program to help select appropriate rates of infusion is being studied.

It is intended that this patient should continue with this system for at least one year to allow her injection sites to recover and in the hope that after this prolonged period in near-normal 
metabolic balance subsequent diabetic management in more conventional forms will be more successful.

Brittle diabetes is remarkable difficult to manage and totally disrupts the life of the patient. Long-term continuous intravenous infusion of insulin using a small portable system allows acceptable metabolic control to be achieved when other methods have failed.

I thank the patient for her cheerful co-operation, the nursing staff of Pinewood Ward for their enthusiastic help; Miss J R Tomlinson for her secretarial help; Dr Kurtz of the Cobbold Laboratories, Middlesex Hospital, for measuring free insulin concentration and insulin binding; Miss A Mansfield for inserting the catheter; and Dr G P Blanshard for allowing me to report on his patient.

\section{References}

1 Watkins PJ. Insulin infusion systems, diabetic control, and microvascular complications. Br Med f 1980;280:350-2.

2 Pirart J. Diabetes mellitus and its degenerative complications: a prospective study of 4400 patients observed between 1947 and 1978 Diabetes Care 1978;1:168, 252.

${ }^{3}$ Pickup JC, Keen H, Parsons JA, Alberti KGMM. Continuous subcutaneous insulin infusion: an approach to achieving normoglycaemia. Br Med f 1978; : 204-7.

+ Pickup JC, White MC, Keen H, Kohner EM, Parsons JA, Alberti KGMM. Long term continuous subcutaneous insulin infusion in diabetics at home. Lancet $1979 ;$ ii :870-3.

5 Pickup JC, Keen H, Parsons JA, Alberti KGMM. Continuous subcutaneous insulin infusion: improved blood glucose and intermediary metabolic control in diabetes. Lancet 1979; i:1255-8.

${ }^{6}$ Tamborlane WV, Sherwin RS, Genel M, Felig P Reduction to normal plasma glucose in juvenile diabetes by subcutaneous administration of insulin with a portable infusion pump. $N$ Engl f Med 1979;300:573-8.

7 Tamborlane WV, Sherwin RS, Genel M, Felig P. Restoration of normal lipid and amino acid metabolism in diabetic patients with a portable insulin infusion pump. Lancet $1979 ; \mathrm{i}: 1258-61$.

' Pickup JC, Home PD, Bilous RW, Keen H, Alberti KGMM. Management of severely brittle diabetes by continuous subcutaneous and intramuscular insulin infusions: evidence for a defect in subcutaneous insulin absorption. $\mathrm{Br} \mathrm{Med} \mathcal{F} 1981$;282:347-50.

${ }^{9}$ Berger M, Halban, PA, Girardier L, Seydoux J, Offord RE. Absorption kinetics of subcutaneously injected insulin: evidence for degradation at the injection sites. Diabetologia 1979;17:97-9.

${ }^{10}$ Anonymous. Subcutaneous injections and absorption of insulin. Lancet 1980;i:1005-6.

${ }^{11}$ Friedenberg GR, White N, Cataland S, O'Dorisio TM, Sotos JF, Santiago JV. Diabetes responsive to intravenous but not subcutaneous insulin: effectiveness of aprotinin. $N$ Engl $\mathcal{F}$ Med 1981;305:363-8.

12 Nakagawa S, Nakayama H, Sasaki T, et al. A simple method for the determination of serum free insulin levels in insulin treated patients. Diabetes $1973 ; 22: 590-600$.

${ }^{13}$ Kurtz AB, Matthews JA, Mustaffa BE, Daggett PR, Nabarro JDN. Decrease of antibodies to insulin, pro-insulin and contaminating hormones after changing treatment from conventional beef to purified pork insulin. Diabetologia 1980;18:147-50.

${ }^{14}$ Heimbach DM, Ivey TD. Technique for placement of a permanent home hyperalimentation catheter. Surg Gynecol Obstet 1976;143:634-6.

15 Bailey MJ. Reduction of catheter-associated sepsis in parenteral nutrition using low-dose intravenous heparin. Br Med f 1979;i:1671-3.

${ }^{16}$ Dandona P, Foster M, Haley F, Greenbury E, Beckett AG. Low dose insulin infusions in diabetic patients with high insulin requirements. Lancet 1978 ;ii :283-5.

${ }^{17}$ Paulsen EP, Courtney JW, Duckworth WC. Insulin resistance caused by massive degradation of subcutaneous insulin. Diabetes 1979;28:640-5.

18 Riella MC, Scribner BH. 5 years' experience with a right atrial catheter for prolonged parenteral nutrition at home. Surg Gynecol Obstet 1976; $143: 205-8$.

(Accepted 26 August 1981)

\title{
Variation in response to cytotoxicity of cigarette smoke
}

\author{
J M HOPKIN, V S TOMLINSON, R M JENKINS
}

\section{Abstract}

The cytotoxic effect of cigarette smoke condensate on human polymorphs was investigated in vitro by the method of vital dye exclusion. Exposure to 1/800 of the smoke from one high-tar cigarette killed a detectable proportion of a population of $10^{6}$ cells. The response among the cells from 40 healthy people varied widely, the percentage of dead cells ranging from $3 \%$ to $66 \%$ and from $17 \%$ to $87 \%$ at exposure levels of $125 \mu \mathrm{g}$ and $250 \mu \mathrm{g}$ cigarette smoke condensate respectively. Differences in individuals' responses were reproducible and unrelated to age or sex or smoking habit. The cells from 10 patients with irreversible obstructive airways disease and probable emphysema were significantly more sensitive than those from 10 patients with no respiratory disability matched for age and smoking habits.

Genetically influenced variation in cellular response to cytotoxicity may be an important determinant of the risk of developing emphysema among smokers.

Department of Medicine, University of Birmingham, Queen Elizabeth Hospital, Birmingham

$\mathrm{J} M$ HOPKIN, MD, lecturer in medicine

V S TOMLINSON, BSC, technician

R M JENKINS, MRCP, medical registrar

\section{Introduction}

Cigarette smoke is the dominant factor in producing lung cancer and emphysema, but many heavy cigarette smokers escape either or both these fates, which suggests that other factors influence outcome after prolonged smoking.

We have shown that individuals vary in their in-vitro cellular responses to DNA damage induced by cigarette smoke, as detected by sister chromatid exchanges. ${ }^{1}$ We have also shown that among smokers this variation in response is related to the risk of developing lung cancer. ${ }^{1}$ These findings are in keeping with the somatic mutational theory of malignant transformation. We report here an investigation into the cytotoxicity of cigarette smoke for human polymorphs to determine whether there was any variation in response and whether this was related to the risk of developing emphysema.

\section{Methods}

Using an automatic smoking machine ${ }^{2}$ we produced cigarette smoke condensates from three popular brands of British cigarettes, one with a high-tar content, one with a middle-tar content, and one with a lowtar content. Each condensate was dissolved in dimethyl sulphoxide $(\mathrm{DMSO})$ at a series of dilutions and stored at $-20^{\circ} \mathrm{C}$ before use. Polymorphs were separated from freshly defibrinated venous blood by sedimentation over Hypaque-Ficoll ${ }^{3}$ and after washing were suspended in samples of $10^{6}$ cells in $1 \mathrm{ml}$ of Ringer's solution. Samples of $10^{6}$ cells were exposed to $5 \mu \mathrm{l}$ of DMSO alone and a series of doses of cigarette smoke condensate each dissolved in $5 \mu 1$ of DMSO. After one hour's incubation at $37^{\circ} \mathrm{C}$, when no cell lysis had occurred, 